\title{
A INFORMATIVIDADE NA SALA DE AULA: INVESTINDO EM ATIVIDADES PARA A PRODUÇÃO DE TEXTOS ARGUMENTATIVOS
}

\author{
THE INFORMATIVITY IN THE CLASSROOM: INVESTING IN ACTIVITIES FOR THE \\ PRODUCTION OF ARGUMENTATIVE TEXTS
}

Aline Rubiane Arnemann ${ }^{1}$ e Cristiano Egger Veçossi ${ }^{2}$

\begin{abstract}
RESUMO: Neste trabalho, analisamos uma atividade desenvolvida durante a pesquisa de Arnemann (2017) que focalizou o princípio de informatividade, com alunos do Ensino Médio noturno, verificando como a articulação entre atividades linguísticas e epilinguísticas contribui para a obtenção de avanços na produção escrita de gêneros argumentativos. $O$ referencial teórico traz autores da Linguística do Texto (LT) no que concerne à informatividade (BEAUGRANDE e DRESSLER, 1981; VAL, 1994), agregando, também, autores da Ciência da Informação (CAPURRO e HJORLAND, 2007; CUNHA, 2001). Ademais, quanto ao ensino e à aprendizagem de Língua Portuguesa, discutimos uma abordagem que prioriza as atividades sobre os exercícios (ENGSTRÖM, 2002), classificando-as em: linguísticas, epilinguísticas e metalinguísticas (FRANCHI, 2006; GERALDI, 1991; TRAVAGLIA, 1995), a qual sustentou a análise. Os resultados revelam avanços na informatividade das produções, os quais se deveram, principalmente, à articulação entre procedimentos de natureza linguística (produção e compreensão de textos) e epilinguística (reflexão a partir da produção).
\end{abstract}

PALAVRAS-CHAVE: informatividade; atividade; produção de texto; linguística do texto.

ABSTRACT: In this work, we analyze an activity developed during Arnemann's research (2017) which focalized the informativity principle with students from nightly high school, verifying how the articulation between linguistic and epilinguistic activities contributes to obtain advances in the written production of argumentative genres. The theoretical referential presents authors of Text Linguistics (LT) with regard to informativity (BEAUGRANDE $e$ DRESSLER, 1981; VAL, 1994), also adding authors of Information Science (CAPURRO $e$ HJORLAND, 2007; CUNHA, 2001). Besides that, regarding the teaching and learning of Portuguese Language, we discuss about the approach, which gave support for the analysis, that prioritize the activities about the exercises (ENGSTRÖM, 2002), classifying them in: linguistics, epilinguistics and metalinguistics (FRANCHI, 2006; GERALDI, 1991; TRAVAGLIA, 1995). The results demonstrate advances regarding the informativity of the productions, which were mainly due to the articulation between procedures of linguistic nature (production and comprehension of textos) and epilinguistic (reflection from production).

\footnotetext{
${ }^{1}$ Mestra em Estudos Linguísticos (UFSM) e doutoranda em Estudos Linguísticos (PPGL/UFSM), integrante do Grupo de Estudos em Linguística do Texto e Ensino (GELTE). Tutora a distância no curso de Letras Licenciatura UaB/UFSM.

${ }^{2}$ Doutor em Letras pela Universidade Federal de Santa Maria. Docente na Escola Estadual de Educação Básica Professora Margarida Lopes, Santa Maria-RS e tutor a distância no Curso de Licenciatura em Letras da UAB/UFSM. Coordenador do GELTE (Grupo de Estudos em Linguística do Texto e Ensino).
} 
KEYWORDS: informativity; activity; text production; textual linguistic

\section{Considerações iniciais}

Surgida na Alemanha, na segunda metade da década de 1960, a Linguística do Texto (doravante LT), inicialmente voltada para o estudo das conexões entre frases (análise transfrástica), foi, ao longo de sua constituição, ampliando a noção de texto, passando a agregar aspectos pragmáticos (segunda metade dos anos 1970), cognitivos (a partir da década de 1980) e discursivos (década de 1990), chegando a uma concepção de natureza sociocognitiva-interacional, segundo a qual o texto é concebido "como lugar de interação entre atores sociais e de construção interacional de sentidos" $(\mathrm{KOCH}, 2017$, p. 12, grifos da autora).

À medida que foi ampliando suas concepções, passando a considerar elementos referentes à interação que circunda a produção e compreensão de textos, muitas das noções teóricas discutidas pela LT foram sendo agregadas pelos documentos oficiais que sustentam o processo de ensino e aprendizagem de Língua Portuguesa (LP). Essa incorporação chegou a seu ápice com a publicação, em 1998, dos Parâmetros Curriculares Nacionais de Língua Portuguesa (BRASIL, 1998). Nesse documento, a centralidade do trabalho com o texto em sala de aula é colocada em primeiro plano, havendo referência a noções basilares da LT tais como: coesão, coerência, intertextualidade, entre outras.

Entretanto, mesmo com uma abordagem do texto como um processo de produção de sentidos, vinte anos após a publicação dos PCNs, “o que poderia configurar uma importante colaboração dos estudos textuais e discursivos para o ensino acaba por diluir-se, devido a teorias pouco compreendidas e mal aplicadas [...]". (GOMES-SANTOS et alii, 2010, p. 325).

Diante desse quadro, como professores e pesquisadores preocupados com as práticas que ocorrem na Escola Básica, podemos contribuir não só com os avanços da ciência linguística como também com o processo escolar de ensino e aprendizagem da língua materna. Para tanto, neste artigo, concentramo-nos na análise de uma prática realizada em sala de aula ao longo de uma pesquisa-ação que culminou na produção da dissertação de mestrado de Arnemann (2017). O trabalho da autora enfocou a noção teórica “informatividade”, com o intuito de contribuir para a qualificação da produção de textos argumentativos de alunos do $3^{\circ}$ ano do Ensino Médio de uma escola pública estadual do interior do Rio Grande do Sul. 
Convém destacarmos que o artigo aqui apresentado não é, exatamente, um recorte da dissertação da autora. O olhar que damos ao processo realizado em Arnemann (2017) visa a enfocar, neste artigo, especificamente uma atividade desenvolvida pela autora ao longo da pesquisa-ação empreendida. Nessa análise, pretendemos demonstrar como atividades de cunho linguístico e epilinguístico (FRANCHI, 2006) foram articuladas no sentido de promover avanços na informatividade das produções escolares dos alunos.

Em termos estruturais, apresentamos, na seção seguinte, uma contextualização sobre o estudo que serviu de base para a presente discussão. Na sequência, enfocamos a informatividade. Em seguida, tratamos da diferença entre a abordagem aqui proposta, focada na noção de "atividade escolar" e a perspectiva (tradicional) que parte do exercício. Além disso, ainda nessa seção, trazemos a categorização de atividades proposta por Franchi (2006). A partir dessa classificação e, não perdendo de vista o princípio da informatividade, na seção posterior, analisamos uma atividade que foi elaborada por Arnemann (2017) com o propósito de possibilitar avanços na informatividade dos textos produzidos pelos estudantes. Por fim, trazemos as considerações finais e as referências teóricas que nos serviram de base nesta produção.

\section{Contextualizando o estudo}

A informatividade, abordada, neste artigo, é decorrente de reflexões realizadas em Arnemann (2017), as quais são ampliadas aqui. Nesse sentido, o objetivo central da referida pesquisa consistiu em "contribuir com o avanço da escrita argumentativa de alunos concluintes do Ensino Médio noturno utilizando o critério de informatividade" (ARNEMANN, 2017, p. 12).

Para dar conta de tal objetivo, via diálogo com representantes de uma escola da rede pública estadual da cidade de Santa Maria - RS e respectiva autorização ${ }^{3}$ tanto dos membros escolares quanto do Comitê de Ética da universidade à qual estava vinculada, a pesquisadora atuou como professora, ao longo dos meses de agosto a dezembro de 2015, de uma turma de terceiro ano de Ensino Médio noturno. Durante esse período, haja vista que o conteúdo programático da disciplina de LP propunha o trabalho com produções textuais argumentativas, a pesquisadora professora abordou esse tópico mediante subsídios buscados na Linguística do Texto, em especial, a informatividade.

\footnotetext{
${ }^{3}$ CAAE 45087515.1.0000.5346.
} 
Ressaltamos que o foco atual da LT está voltado para o estudo do texto, tanto no viés de compreensão como de produção, em sala de aula. Assim, em Arnemann (2017), realizamos o levantamento do estado da questão no que tange a pesquisas que envolvem informatividade em âmbito nacional. De acordo com os trabalhos que consultamos na época, a saber, Val (1994), Ferreira (2000), Santos (2002), Manzoni (2007), Nóbrega (2010), Raick (2013) e Araújo (2015), verificamos que nenhum deles utiliza esse princípio no processo de ensino e aprendizagem de produção textual. Diferentemente disso, observam o referido fator em textos produto, apontando, na maioria dos casos, que a escrita de estudantes da escola básica apresenta baixa informatividade.

Dentre tais estudos, destacamos: Val (1994), que realiza ampliações a partir de Beaugrande e Dressler (1981) e, diante disso, serviu-nos de aporte teórico; e Manzoni (2007), a qual propõe que textos base devem ser utilizados em sala de aula a fim de que os estudantes tenham onde buscar informações para utilizar em suas produções. A proposta dessa autora foi empregada na pesquisa de mestrado.

Koch (2015) defende que, para compreender e explicar o texto enquanto entidade multifacetada, a LT "sente necessidade de intensificar sempre mais o diálogo que já vem se travando com as demais Ciências - e não só as Humanas -, transformando-se numa 'ciência integrativa" (KOCH, 2015, p. 194). Diante da disposição da autora, investimos na articulação com outras teorias.

Assim, em Arnemann (2017), buscamos apoio na Ciência da Informação (CI), representada por Capurro e Hjorland (2007) para compreender o termo “informação" e por Cunha (2001) para alicerçar o tratamento acerca das fontes de informação. Na Teoria da Argumentação (TA), consoante Perelman e Olbrechts-Tyteca (2014), respaldamo-nos nas questões referentes ao argumento de autoridade e aos lugares da argumentação. O diálogo da LT com a CI e a TA nos forneceu a base para elaborar as categorias de análise, as quais estão organizadas em um quadro que é abordado a posteriori.

Visto que a pesquisadora atuou com os participantes ao longo de um período a fim de alterar um cenário no que concerne à escrita dos estudantes, utilizamos a Pesquisa-ação como metodologia, no viés de Thiollent (2011). Essa metodologia dispõe que há um trabalho colaborativo e corresponsável entre pesquisador e participantes do estudo.

Durante a intervenção com os terceiranistas, foi construído um instrumento didático para auxiliá-los a autogerenciar seu processo de aprendizagem de escrita argumentativa: o Diário de Produção Textual (DPT), o qual continha um Jogo de Produção Textual e reunia os 
textos produzidos pelos discentes - cada discente tinha o seu DPT. Realizada tal contextualização, passamos ao tratamento da informatividade.

\section{Informatividade}

Beaugrande e Dressler (1981) dispõem que um texto, para se constituir como tal, demanda apresentar textualidade e ser observado no todo. O texto é comparado a um tecido, pois esse, se desmembrado, deixa de sê-lo e se torna um emaranhado de fios; assim, se observado em partes, o texto se torna um conjunto de frases e orações. Nesse sentido, os teóricos propõem sete fatores de textualidade: coesão, coerência, aceitabilidade, intencionalidade, situacionalidade, intertextualidade e informatividade, sendo o nosso foco esse último fator.

Os teóricos alemães, ao proporem tal princípio, recorrem à CI. Para tanto, embasam-se nas proposições de Shannon e Weaver (1949), os quais discutem acerca da noção de probabilidade estatística, em que "quanto maior o número de alternativas possíveis em um dado ponto, maior será o valor de informação quando uma delas for escolhida", (BEAUGRANDE e DRESSLER, 1981, p. 140) ${ }^{5}$.

Esses autores consideram viável substituir a noção de probabilidade estatística pela de probabilidade contextual. Ao realizar essa substituição, a atenção se volta a questões do mundo real, a fatos, os quais não são percebidos como experiências individuais, mas de modo integrado. Assim, Beaugrande e Dressler (1981, p.139) designam a informatividade como a “extensão à qual uma apresentação ${ }^{6}$ é nova ou inesperada pelos receptores"7

As informações, podem ser esperadas ou inesperadas. Nesse sentido, os autores investem em uma escala de possibilidades gerais e, a partir daí, propõem que as escalas podem ser de três ordens, as quais consistem nos três graus de informatividade: baixo, médio ou aparentemente fora do conjunto como um todo. Em consonância com os teóricos, um exemplo de primeira ordem (grau baixo), diante de sua previsibilidade, seria o texto "PARE" presente em uma placa de trânsito. Além disso, a primeira ordem pode constar em qualquer texto, estando ou não presentes as outras.

\footnotetext{
4 "The greater the number of possible alternatives at given point, the higher will be the information value when one of them is chosen."

${ }^{5}$ Todas as traduções deste artigo são de nossa responsabilidade.

${ }^{6}$ Em Arnemann (2017), optou-se por não utilizar o termo "apresentação" e sim "informação", o qual mantemos aqui.

7 "Extent to which a presentation is new or unexpected for the receivers."
} 
Já as ocorrências de segunda ordem se efetivam no momento em que as preferências ou padrões são substituídos, de modo que a probabilidade das ocorrências é rebaixada de uma escala mais alta. Por sua vez, as ocorrências que "parecem estar fora do grupo de opções mais ou menos prováveis, transmitem informatividade de terceira ordem ${ }^{8}$ " (BEAUGRANDE e DRESSLER, 1981, p. 144, grifo do autor). De acordo com os estudiosos, essas ocorrências demandam mais atenção e fontes de processamento, todavia são mais interessantes. Nesse sentido, os teóricos defendem que podem ser rebaixadas para a segunda ordem (grau médio), o que levaria a facilitar a compreensão por parte do leitor. Essas três ordens, ou seja, os três graus de informatividade, dizem respeito à probabilidade contextual.

Os autores ressalvam que saber qual é a expectativa do usuário de texto não é uma tarefa simples, pois nem sempre o interlocutor ${ }^{9}$ revela o que espera. Beaugrande e Dressler (1981, p. 160) discutem a informatividade como "a extensão para a qual os materiais apresentados são novos ou inesperados, os controles importantes empregados na seleção e organização de opções do texto ${ }^{10}$ " e asseveram que o grau médio configuraria o padrão usual de informatividade. Assim, as informações novas e dadas devem ser balanceadas a fim de que o interlocutor compreenda o texto. Val (1994) dispõe que a suficiência de dados, ou seja, os dados que permitem confirmar informações, auxilia no balanceamento de informações.

Nesse sentido, visto que o objetivo da dissertação de mestrado estava voltado para o processo de ensino e aprendizagem de texto argumentativo utilizando a informatividade, realizamos algumas adaptações e articulações com outras teorias para viabilizar a execução de tal processo. No que tange a adaptações, não investimos no grau médio de informatividade, mas no grau alto. Adotamos esse posicionamento, ao buscar alicerce em Cunha (2001), nas fontes (também chamadas de documentos) de informação primária, secundária e terciária.

A fonte primária diz respeito a "novas informações ou novos documentos primários: contém, principalmente, novas informações ou novas interpretações de ideias e/ou fatos acontecidos" (CUNHA, 2001, p. ix). Já a fonte secundária serve como facilitadora na compreensão do leitor sobre informações de fonte primária. Em sua instância, a fonte terciária "têm como função principal ajudar o leitor na pesquisa de fontes primárias e secundárias, sendo que, na maioria, não trazem nenhum conhecimento ou assunto como um todo, isto é, são sinalizadores, além de informação factual (CUNHA, 2001, p. ix).

\footnotetext{
8 "Occurrences which at first appear to be outside the set of more or less probable options convey third-order informativity."

${ }^{9}$ Beaugrande e Dressler (1981) utilizam o termo receptor, todavia, diante da posição atual da LT, optamos por utilizar o termo interlocutor, pois concebe a interação entre os envolvidos na comunicação.

10 "The extent to which presented materials are new or unexpected, exerts important controls on the selection and arrangement of options in texts."
} 
A partir dessas considerações, articulamos cada uma dessas fontes aos graus de informatividade, a fim de que os estudantes aprendessem a trabalhar com informações e compreendessem a fonte que buscavam para empregar em suas produções textuais, pois a fonte intervém na argumentatividade do texto. Ainda, em função de enfatizarmos o caráter argumentativo dos textos, atentamos para a questão do argumento de autoridade, o qual "utiliza atos ou juízos de uma pessoa ou de um grupo de pessoas como meio de prova a favor de uma tese" (PERELMAN e OLBRECHTS-TYTECA, 2014, p. 348). Desse modo, investimos na observação da fonte da informação, da autoridade autoral e do meio em que foi veiculada. Tal articulação deu origem às categorias de análise em Arnemann (2017) e pode ser contemplada no quadro a seguir:

\begin{tabular}{|c|c|c|c|c|}
\hline $\begin{array}{l}\text { Quadro } \\
\text { Autoavaliativo }\end{array}$ & Subfases & & $\begin{array}{l}\text { Em qual fase } \\
\text { e nível está } \\
\text { seu texto? }\end{array}$ & Indique \\
\hline \multirow{8}{*}{$\begin{array}{l}\text { Grau baixo de } \\
\text { informatividade }\end{array}$} & Nível 1.1 & $\begin{array}{l}\text { Não apresentei informação } \\
\text { argumento. }\end{array}$ & $\begin{array}{ll}\text { Texto } & \mathbf{1} \\
\text { Escrita } & \end{array}$ & \\
\hline & Nível 1.2 & $\begin{array}{l}\text { Apresentei informação, mas não há uma } \\
\text { relação entre a materialidade linguística dela } \\
\text { e do argumento. }\end{array}$ & $\begin{array}{l}\text { Texto 1 } \\
\text { Reescrita }\end{array}$ & \\
\hline & Nível 1.3 & $\begin{array}{l}\text { Apresentei informação, mas não há uma } \\
\text { relação entre o contexto dela } \\
\text { argumento. }\end{array}$ & $\begin{array}{l}\text { Texto } \\
\text { Escrita }\end{array}$ & \\
\hline & Nível 1.4 & $\begin{array}{l}\text { Apresentei informação, mas ela está baseada } \\
\text { em uma experiência pessoal. }\end{array}$ & $\begin{array}{l}\text { Texto 2 } \\
\text { Reescrita }\end{array}$ & \\
\hline & Nível 1.5 & $\begin{array}{l}\text { Apresentei informação, mas ela está baseada } \\
\text { em dados corriqueiros que observo no meu } \\
\text { dia a dia. }\end{array}$ & $\begin{array}{l}\text { Texto } \\
\text { Escrita }\end{array}$ & \\
\hline & Nível 1.6 & $\begin{array}{l}\text { Apresentei informação que foi veiculada por } \\
\text { uma fonte terciária de informações, cujo } \\
\text { autor da redação oral ou escrita não é } \\
\text { autoridade no assunto abordado na } \\
\text { informação. }\end{array}$ & $\begin{array}{l}\text { Texto 3 } \\
\text { Reescrita }\end{array}$ & \\
\hline & Nível 1.7 & $\begin{array}{l}\text { Apresentei informação que foi veiculada por } \\
\text { uma fonte secundária de informações, cujo } \\
\text { autor da redação oral ou escrita não é } \\
\text { autoridade no assunto abordado na } \\
\text { informação. }\end{array}$ & & \\
\hline & Nível 1.8 & $\begin{array}{l}\text { Apresentei informação que foi veiculada por } \\
\text { uma fonte primária de informações, cujo } \\
\text { autor da redação oral ou escrita não é } \\
\text { autoridade no assunto abordado na } \\
\text { informação. }\end{array}$ & & \\
\hline $\begin{array}{l}\text { FASE } 2 \\
\text { Grau médio de } \\
\text { informatividade }\end{array}$ & Nível 2.1 & $\begin{array}{l}\text { Apresentei informação que foi veiculada por } \\
\text { uma fonte terciária de informações, cujo } \\
\text { autor da redação oral ou escrita é autoridade } \\
\text { no assunto abordado na informação. }\end{array}$ & & \\
\hline \multirow[t]{2}{*}{$\begin{array}{l}\text { FASE } 3 \\
\text { Grau alto de } \\
\text { informatividade }\end{array}$} & Nível 3.1 & $\begin{array}{l}\text { Apresentei informação que foi veiculada por } \\
\text { uma fonte secundária de informações, cujo } \\
\text { autor da redação oral ou escrita é autoridade } \\
\text { no assunto abordado na informação. }\end{array}$ & & \\
\hline & Nível 3.2 & Apresentei informação que foi veiculada por & & \\
\hline
\end{tabular}




\begin{tabular}{|l|l|l|l|l|}
\hline & $\begin{array}{l}\text { uma fonte primária de informações, cujo } \\
\text { autor da redação oral ou escrita é autoridade } \\
\text { no assunto abordado na informação. }\end{array}$ & $\mid$ \\
\hline
\end{tabular}

Figura 1 - Quadro Autoavaliativo

A Figura 1 apresenta uma gradação de subcategorias, do nível 1.1 ao nível 3.2. Essas subcategorias têm a função de auxiliar o estudante a identificar informações presentes em suas produções, o autor e a natureza da fonte em que foi veiculada. As cores exercem função sinalizadora do grau, a penúltima coluna indica a produção que o estudante está atentando e a última reserva um espaço para o estudante assinalar o nível de informatividade que percebe em seu texto. Dessa maneira, a Figura 1 promove o autogerenciamento do estudante em relação ao seu processo de aprendizagem textual. Esse modo sistematizado de trabalhar o texto, envolvendo o DPT, que contém o referido quadro, revela a concepção de trabalho com atividades, conforme discutimos na sequência.

\section{As atividades na aula de Língua Portuguesa}

Para iniciar uma reflexão acerca da realização de atividades de produção textual na aula de LP, é preciso, antes de mais nada, esclarecermos o que estamos compreendendo aqui por "atividade". Observando a discussão proposta por Engström (2002) acerca do que o autor denomina "encapsulação da atividade escolar" e, levando em conta nosso conhecimento sobre o processo de ensino e aprendizagem na escola básica, percebemos que as dificuldades enfrentadas pelos estudantes são, muitas vezes, o resultado de práticas escolares organizadas em torno de "tarefas discretas" (p. 181), nas quais a compartimentalização dificulta que os alunos percebam as conexões existentes entre os aspectos que compõem determinado processo.

Nesse caso, o desenho que apresentamos remete para a perspectiva do mero "exercício escolar", com função, na maioria das vezes, de verificação do que foi aprendido após determinada "lição" passada pelo professor. Cerqueira (2010), a partir da análise de manuais didáticos e da observação de aulas de LP na Escola Básica, assevera que o trabalho com a produção de textos escritos em sala de aula tem privilegiado o exercício.

Observando a diferença existente entre esse emprego (meramente verificacionista), que está na base do exercício e o que podemos considerar uma verdadeira "atividade" de 
ensino, reportamo-nos a alguns aspectos centrais da Teoria da Atividade ${ }^{11}$. Essa, inicialmente desenvolvida por Vygotsky, passou por significativos avanços com Leontiev e, posteriormente, com Engström. De suas noções essenciais, interessa-nos aqui a ideia de um sujeito que, de forma individual ou coletiva, objetiva transformar um objeto, utilizando, para tanto, uma ferramenta mediadora. Nesse caso, o que orienta a atividade é um motivo, o qual demanda uma série de ações articuladas (KOZULIN, 2002).

Pensando na situação de ensino e aprendizagem que se coloca no contexto escolar, destacamos algumas questões que nos parecem essenciais. Em sentido amplo, trazendo à baila a noção de mediação (VYGOTSKY, 1987), percebemos que, na escola, é o professor, "parceiro mais competente" na relação docente-discente, que engendra uma série de procedimentos articulados, os quais, no seu todo, visam a que o estudante atinja determinados propósitos de aprendizagem.

No caso das atividades realizadas na aula de LP, observamos que se organizam em três eixos principais: leitura, produção de texto e gramática, havendo, muitas vezes, ênfase sobre esse último núcleo, o qual, de forma desconectada, passa a ser compreendido como "aula de português", sem que haja a devida inter-relação com leitura e escrita. Assim, os conteúdos gramaticais são postos estritamente como nomenclaturas, sem que o processo conduza para uma reflexão sobre o funcionamento de tais estruturas na produção e compreensão de textos.

$\mathrm{Na}$ tentativa de superar essa fragmentação, a qual acaba por se fortalecer pelo nítido desequilíbrio entre os três polos (supremacia do ensino gramatical sobre as demais dimensões), é que, nas práticas de ensino que mobilizaram a presente discussão, o objeto é a produção de textos argumentativos, em que se destacou o trabalho com a informatividade. Nesse caso, a principal ferramenta mediadora compõe-se da Figura 1, elaborado pela pesquisadora, com o intuito de que o estudante pudesse avaliar seu desempenho ao longo das versões produzidas para seu texto. Desse modo, como procedimentos componentes da atividade, foram proporcionados tanto momentos em que os alunos deveriam efetivamente escrever, produzir textos verbais, como também situações nas quais deveriam pensar sobre as operações linguísticas que estavam realizando. Fica claro, aqui, que a atividade de produção textual, tal como planejada pela docente, visa a recuperar, no contexto da sala de aula, as ações que compõem a produção de um texto fora dos muros escolares.

\footnotetext{
11 Temos consciência de que as postulações referentes à Teoria da Atividade vão muito além do recorte teórico aqui apresentado. No entanto, optamos por nos concentrarmos no que nos parece ser o aspecto fundamental de seus escritos levando em conta a discussão proposta neste artigo.
} 
Esse caminho que foi traçado visando à superação da fragmentação no ensino encontra respaldo teórico na classificação de atividades proposta por Franchi (2006) ${ }^{12}$, a qual foi retomada por Geraldi (1991) e por Travaglia (1995). Com relação às atividades realizadas na aula de LP, especialmente no sentido de articular leitura, produção escrita e gramática, Franchi distingue três tipos: atividade linguística, atividade epilinguística e atividade metalinguística.

Atividades linguísticas são aquelas que envolvem alguma forma de produção e/ou compreensão de linguagem, oralmente ou por escrito. Franchi (2006) acrescenta que demandam a criação de um ambiente escolar rico em interações, orais e escritas, propício para que os falantes produzam linguagem. Travaglia (1995, p. 34) assim sintetiza: "as atividades linguísticas são, pois, as atividades de construção e/ou reconstrução do texto que o usuário realiza para se comunicar".

Com relação às atividades epilinguísticas, dizem respeito "a essa prática que opera sobre a própria linguagem, compara as expressões, transforma-as, experimenta novos modos de construção canônicos ou não, brinca com a linguagem, investe as formas linguísticas de novas significações" (FRANCHI, 2006, p. 97). Nos textos escritos, configuram-se como atividades desse tipo aquelas que envolvam operações como resumo, expansão de um texto e paráfrase de determinado excerto. O autor (2006, p. 98) acrescenta que esse tipo de atividade fica "melhor ainda quando supõe a participação, a contribuição, a crítica recíproca, a escolha".

Já as atividades metalinguísticas envolvem a sistematização das estruturas, na qual a linguagem é descrita "em um quadro nocional intuitivo ou teórico" (FRANCHI, 2006, p. 98). Detalhando essa categoria, Travaglia (1995, p. 35) esclarece que "todos os estudiosos e especialistas da língua fazem metalinguagem, todas as gramáticas descritivas, históricas, comparadas, geral, universal ou de outros tipos são produto de atividade metalinguística".

Na seção seguinte, passamos à análise de uma atividade realizada ao longo do trabalho mestrado de Arnemann (2017). Para tanto, empregamos essa classificação de Franchi (2006), procurando verificar, ao longo dos procedimentos didáticos adotados, de que modo foram sendo articuladas especialmente atividades de cunho linguístico e epilinguístico, já que, considerando os propósitos da pesquisa da autora, as de natureza metalinguística não foram enfatizadas.

\footnotetext{
12 O texto original é de 1988.
} 


\section{Análise e discussão}

Após termos apresentado uma contextualização sobre o estudo de Arnemann (2017), bem como situado os principais pontos acerca da informatividade e da questão da atividade no ensino de língua materna, procedemos, neste espaço, à análise dos procedimentos que compuseram a atividade desenvolvida, junto aos alunos, na dissertação que serviu de base para este trabalho. Isso posto, concentramos nosso olhar sobre os doze passos descritos na sequência didática que se encontra em anexo.

Destacamos que os procedimentos que compõem a sequência didática 06 encaminham uma verdadeira atividade (e não um mero exercício escolar), haja vista que se encontram articulados, tendo como alvo um motivo maior: a produção de um texto argumentativo, do gênero artigo de opinião, sobre o tema "escolha profissional". Nesse sentido, os passos partem de um momento cuja intenção é despertar a atenção dos alunos com relação ao tema da produção (1), passando pela busca de informações, seja por meio de experiências pessoais dos estudantes (2), seja com base em uma fonte habilitada para tratar da temática em pauta (3).

Quanto ao passo (4), sinalizamos que, em meio às atividades linguísticas realizadas até o momento (leitura e produção oral), configura-se como uma atividade epilinguística, pois envolve a análise por parte dos estudantes, para posterior classificação do tipo de fonte do texto-base. Ademais, no que se refere, especificamente, à informatividade, é o momento em que os estudantes mobilizam seus conhecimentos em construção acerca desse princípio.

$\mathrm{Na}$ sequência, os passos (5), (6), (7) e (8) correspondem a atividades de caráter linguístico. No que concerne à informatividade, o passo (5) demanda a articulação das informações dadas às novas, via discussão oral. Os passos (6) e (7) convidam o estudante a se inserir em uma situação comunicativa referente ao tema. No passo (8), o aluno é incitado a se posicionar, por escrito, com relação ao assunto da produção, realizando os procedimentos de busca, seleção e balanceamento de informações.

Já nos passos seguintes, a partir da devolução das produções com perguntas problematizadoras (9), tem início uma série de operações epilinguísticas: os estudantes precisam fazer uma análise do que escreveram na primeira produção (10), considerando a intervenção da professora, a fim de proceder à reescrita do texto (11) e, posteriormente, ao retorno à análise do artigo produzido (12). No passo (10), o discente autogerencia seus conhecimentos, o que contribui para a reflexão sobre os aspectos a serem qualificados na reescrita (11). 
Salientamos também os procedimentos epilinguísticos envolvendo o DPT (passos 10 e 12), por meio dos quais os alunos foram mobilizados a identificar o estágio em que se encontravam no jogo com base no grau de informatividade de suas produções, o que fortalece o desenvolvimento da habilidade de autogerenciamento pelo estudante. No passo (12), o discente pode comparar se houve ou não avanços da escrita para a reescrita.

Para melhor ilustrar o desenvolvimento dos procedimentos ao longo da atividade, enfatizando o trabalho com a informatividade, elaboramos a Figura 2:

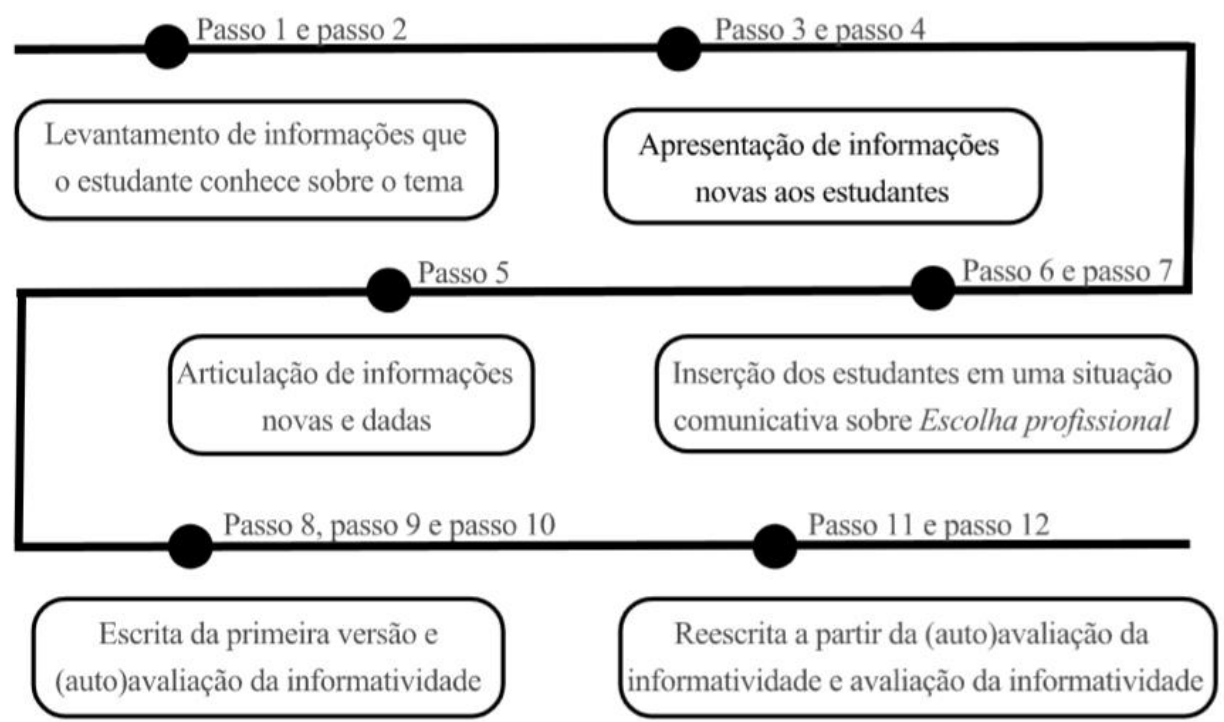

Figura 2 - $\mathrm{O}$ trabalho com a informatividade ao longo dos passos da atividade

Ainda com relação ao DPT, cabe destacar que, da forma como está organizado, o jogo exige a realização de operações epilinguísticas, por parte do estudante, que mobilizam diversos conhecimentos não somente acerca da informatividade (fontes de informação primária, secundária e terciária) como também referentes à argumentação (distinção entre informação e argumento). Para que possa, efetivamente, jogar, o estudante precisa observar com atenção o seu percurso ao longo das produções, realizando julgamentos com base nas fases e níveis em que se encontra o seu texto, o que, ao longo do processo, vai aumentando a autopercepção, de modo que o movimento de pensar sobre o próprio texto passe a se tornar uma prática constante, um importante momento do processo de produção textual. 


\section{Considerações finais}

Neste artigo, partimos de um trabalho que enfocou a informatividade como possibilidade de promover avanços em escritas argumentativas, o qual só foi passível de realização pela adoção de uma concepção que entende a escrita como um processo. Tal compreensão está em consonância com as orientações dadas pelos PCNs para o ensino de LP. Nesse sentido, foi adotada uma abordagem que prioriza a atividade sobre o exercício, sendo essa compreendida como uma série de ações articuladas visando à consecução de determinado propósito.

No caso da investigação realizada, com o intento de proporcionar uma série de procedimentos, buscando que o trabalho com o texto em sala de aula se aproxime ao máximo do modo como se produzem textos fora do ambiente escolar, a professora pesquisadora engendrou diversas ações, sequenciadas e sistematizadas, as quais envolveram tanto atividades linguísticas (produção e compreensão de textos) como epilinguísticas (reflexão a partir do que foi produzido). Dentre esses passos didáticos, destacamos o DPT, instrumento que possibilitou que os estudantes autogerenciassem seu processo de aprendizagem textual argumentativa, a partir da leitura de suas produções e reflexão sobre os aspectos que ainda poderiam ser qualificados.

As reflexões aqui realizadas, as quais partem da dissertação de Arnemann (2017), demonstram que a perspectiva sociocognitivo-interacional sobre o texto, adotada pela LT, é capaz de dar respaldo teórico para práticas de sala de aula, envolvendo atividades de compreensão e produção de textos. O trabalho desenvolvido pela autora explorou um princípio de textualidade, a informatividade, buscando apoio, também, na Ciência da Informação. De igual maneira, outras noções oriundas da LT podem ser consideradas (coesão, coerência, intertextualidade, aceitabilidade, situacionalidade, intencionalidade, progressão, referenciação, etc.), sendo agregados, quando necessário, outros escopos teóricos, dado o caráter interdisciplinar da LT. O essencial é que não se perca a centralização do trabalho com o texto como processo.

\section{REFERENCIAS}

ARAÚJO, Adélia Luciana Rangel Botêlho de. Produção do gênero artigo de opinião no Ensino Fundamental através de sequências didáticas. 2015, 194 p. Dissertação (Mestrado Profissional em Letras) - Universidade Federal da Paraíba, Mamanguape, 2015. 
ARNEMANN, Aline Rubiane. Informatividade na escrita argumentativa de terceiranistas de Ensino Médio noturno: um trabalho de autogerenciamento pautado pela Pesquisa-ação. 2017. 289 p. Dissertação (Mestrado em Estudos Linguísticos) - Universidade Federal de Santa Maria, Rio Grande do Sul, 2017.

BEAUGRANDE, Robert de.; DRESSLER, Wolfgang. Introduction to Text Linguistics. New York: Longman, 1981.

BRASIL. Secretaria de Educação Fundamental. Parâmetros Curriculares Nacionais: terceiro e quarto ciclos do ensino fundamental: língua portuguesa. Brasília MEC/SEF: 1998.

CAPURRO, Rafael; HJORLAND, Birger. O conceito de informação. Perspectivas em Ciência da Informação. Belo Horizonte. v. 12, n.1, p. 148-207, jan./abr. 2007. Disponível em: <http://portaldeperiodicos.eci.ufmg.br/index.php/pci/issue/view/27>. Acesso em: 17 de out. de 2015.

CERQUEIRA, Mirian Santos de. Atividade versus exercício: concepções teóricas e a prática da produção textual no ensino de língua portuguesa. Trabalhos em Linguística Aplicada. Campinas. v. 49, n.1, p. 129-143. jan./jun. 2010. Disponível em: <https://periodicos.sbu.unicamp.br/ojs/index.php/tla/article/view/8645296>. Acesso em: 22 de fev. de 2018.

CUNHA, Murilo Bastos da. Para saber mais: fontes de informação em ciência e tecnologia. Brasília: Briquet, 2001.

ENGSTRÖM, Yrjö. Non scolae sed vitae discimus: Como superar a encapsulação da aprendizagem escolar. In: DANIELS, Harry. (Org.). Uma introdução a Vygotsky. São Paulo: Edições Loyola, 2002.

FERREIRA, Isaac. Coerência, informatividade e ensino: uma reflexão e estudo em textos de professores do Ensino Fundamental. 2000, 148 p. Dissertação (Mestrado em Linguística) Universidade Federal de Santa Catarina, Florianópolis, 2000.

FRANCHI, Carlos. Criatividade e gramática. In: . Mas o que é mesmo "gramática"?. São Paulo: Parábola Editorial, 2006.

GERALDI, João Wanderley. Portos de passagem. São Paulo: Martins Fontes, 1991.

GOMES-SANTOS, Sandoval Nonato. et alii. A contribuição da(s) teoria(s) do texto para o ensino. In: BENTES, Anna Christina; LEITE, Marli Quadros (Orgs.). Linguística de texto e análise da conversação: panorama das pesquisas no Brasil. São Paulo: Cortez, 2010.

$\mathrm{KOCH}$, Ingedore Grunfeld Villaça. Desvendando os segredos do texto. 8. ed. São Paulo: Cortez, 2015.

. Introdução à linguística textual: trajetória e grandes temas. 2. ed. São Paulo: Contexto, 2017.

KOZULIN, Alex. O conceito de atividade na psicologia soviética: Vygotsky, seus discípulos, seus críticos. In: DANIELS, Harry. (Org.). Uma introdução a Vygotsky. São Paulo: Edições Loyola, 2002.

MANZONI, Rosa Maria. Reflexões sobre o papel da informatividade e da organização do pensamento na produção de textos escritos escolares. In: TOLEDO, Eunice Lopes de Souza; SPEERA, Jeane. Mari Santana. Linguística Textual: Literatura, relações textuais, ensino. São Paulo: Arte e Ciência, 2007, p. 185-196.

NÓBREGA, Cristiane Maria Praxedes de Sousa. Anáfora pronominal e repetição lexical: estudo no contexto da produção textual de $9^{\circ}$ ano do ensino fundamental. 2010. 138 p. Dissertação (Mestrado em Linguística Aplicada) - Universidade Federal do Rio Grande do Norte, Natal, 2010.

PERELMAN, Chaïm; OLBRECHTS-TYTECA, Lucie. Tratado da Argumentação: A Nova Retórica. Tradução de Maria Ermantina de Almeida Prado Galvão. 3. ed. São Paulo: Martins Fontes, 2014. 
RAICK, Valéria Cristina Andrade. A produção do texto argumentativo na sala de aula: aspectos ligados à informatividade. 2013. 107 p. Dissertação (Mestrado em Estudos de Língua) - Universidade do Estado do Rio de Janeiro, Rio de Janeiro, 2013.

SANTOS, Eugênio Pacelli Jerônimo. Produção textual no Ensino Médio: uma análise da informatividade. 2002. 131 p. Dissertação (Mestrado em Linguística) - Universidade Federal de Pernambuco, Recife, 2002.

THIOLLENT, Michel. Metodologia da Pesquisa-ação. 18. ed. São Paulo: Cortez, 2011.

TRAVAGLIA, Luiz Carlos. Gramática e interação: uma proposta para o ensino de gramática no $1^{\circ}$ e $2^{\circ}$ graus. São Paulo: Cortez, 1995.

VAL, Maria da Graça Costa. Redação e textualidade. São Paulo: Martins Fontes, 1994. VYGOTSKY, Lev. Semyonovich. Pensamento e linguagem. São Paulo: Martins Fontes, 1987.

\section{ANEXO 1 \\ SEQUÊNCIA DIDÁTICA 06}

Tema: Produção textual de artigo de opinião

Passos:

(1) Provocação por meio de perguntas oralizadas sobre o tema da produção: escolha profissional.

(2) Discussão mobilizada a partir das perguntas, com base nas experiências dos estudantes.

(3) Leitura de uma reportagem de autoria de uma psicóloga sobre o tema em pauta.

(4) Identificação da fonte do texto-base ${ }^{13}$ (primária, secundária ou terciária).

(5) Discussão voltada para a exposição de opiniões pessoais dos estudantes acerca das ideias apresentadas no texto.

(6) Audição do poema “E agora, José?", de Carlos Drummond de Andrade.

(7) Leitura do comando para a produção textual:

O poeta Carlos Drummond de Andrade indaga, em seu poema E agora, José?, um sujeito sobre inúmeras coisas. Imaginemos que Drummond tivesse feito o poema para você, substituindo José pelo seu nome - E agora, fulano?. Faço essa pergunta a você, “e agora, fulano?”. E agora fulano, o ensino médio está acabando, o futuro está ali, bem pertinho, o que você vai fazer? Escreva um artigo de opinião revelando sua opinião favorável ou contrária sobre a decisão da escolha profissional nessa época da sua vida. Você acredita que a profissão que você vai seguir deve ser definida nesse momento da sua vida? Apresente argumentos em seu texto, comprove-os com informações, pois sua opinião é importante para outros jovens que ainda estão indecisos.

\footnotetext{
${ }^{13}$ Conteúdo referente à informatividade, trabalhado ao longo das aulas anteriores.
} 
(8) Momento destinado à escrita da primeira versão do texto.

(9) Feedback: devolução dos textos com perguntas problematizadoras, a fim de promover a reflexão do estudante sobre sua produção.

(10) Diário de Produção Textual - Porque o jogo é meu: identificação, pelo estudante, da fase em que se encontra no jogo com base no grau de informatividade, com vistas à projeção de avanços em sua produção.

(11) Momento destinado à reescrita dos artigos de opinião.

(12) Retorno ao Diário de Produção Textual - Porque o jogo é meu para observar se houve avanços com relação à informatividade na segunda versão do texto.

Recebido em 26/03/2018. Aceito em 02/06/2018. 